\title{
A STUDY ON AWARENESS OF "LEGALLY ACCEPTED AGE LIMITS" AMONG SCHOOL CHILDREN IN KANDY DISTRICT SRI LANKA
}

\author{
Vadysinghe A.N. ${ }^{1}$, Munasinghe A. ${ }^{2}$, Abeysekera $Y .^{3}$, Premasinghe $\mathrm{K}^{4}$, \\ Gamage S.M.K. ${ }^{5}$, Dassanayaka P.B. ${ }^{6}$ \\ ${ }^{1}$ Senior Lecturer, ${ }^{2,3,4,5}$ Temporary Lecturer, Department of Forensic Medicine, \\ Faculty of Medicine, University of Peradeniya, Sri Lanka \\ ${ }^{6}$ Consultant Judicial Medical officer, JMO office, Panadura, Sri Lanka
}

\section{INTRODUCTION}

"Age" is an important element in many of our activities and criminal offences. Admissions to school, marriage, driving license etc. are some examples. However according to Sri Lankan law there are legally accepted age limits for such activities, for example, consent for sexual act, age of marriage, selling of liquor, employment etc. Therefore age is a critical factor for most of the offences against children that can result in various forms of child abuse. $31 \%$ of total population of Sri Lanka consists of children (age 0-18 years). ${ }^{1}$

Child abuse is often considered to demonstrate an iceberg phenomenon and only a small proportion found to be seen above the surface. ${ }^{2}$ In year 2009, more than 4000 cases or nearly $30 \%$ of all cases pending before the High Courts are related to chid abuse, a survey undertaken by the Ministry of Justice and Law Reforms has revealed. ${ }^{3}$ And with each year the numbers of child abuse including child sexual abuse have increased dramatically. The National Child Protection Authority (NCPA) has received 1271 complaints in the year 2008 and that these complaints have been classed as C.A (Child Abuse) and C.R (Child Rights Abuse). Of these 1271 complaints, 511 have been classed as C.A. and 760 have been classed as C.R. The NCPA has already received 793 complaints on child abuse, cruelty and a range of other perversions up to July in $2009 .^{4}$

Police statistics show the total number of child rape cases in 2011 as 1,463 and the figure jumped to 1,759 cases in 2012. These records also reveal a total of over 2,000 sexual offenses against children, besides rape, in 2011 and the child-molestation cases in 2012 soared to over $5,000 .{ }^{5}$ The total number of all crimes against children, which besides sex crimes include crimes of violence, abduction, trafficking and other offenses which increased by a dramatic $64 \%$ between 2011 and $2012 .^{5}$

Therefore child abuse and maltreatment is an increasing problem in Sri Lanka and it is rapidly becoming a global problem.

When reviewing the available literature done to assess the education level of victims and perpetrators of sexual abuse, majority of victims were in the school going age and it has been showed that the education level of both victims and perpetrators were very low. $\mathbf{6 , 7 , 8 , 9}^{-1}$

Although no organization - government or non-government, or even those working in the field of child sexual abuse are able to give proper statistics of the incidence in Sri Lanka few studies done in Sri Lanka among teens and undergraduates revealed that considerable amount have been abused in their life. A study on child abuse in Anuradhapura, Colombo South and Ratnapura revealed that girls were at a higher risk of being abused than the boys especially in the 14-16 age groups. Furthermore affected victims belonged to the school going age or more than 5 years old..$^{10,11}$

Also in our experience both the victims and perpetrators of sexual abuse are underage and more commonly they belong to the school going age. This pattern is seen in both local and international studies. ${ }^{7,8}$ Most children and teens are not aware that some acts they perform are contrary to the law. A study done to assess the awareness of medico-legal issues in victims and 
assailants of alleged sexual abuse by the author has revealed grossly inadequate knowledge on both parties.' That study assessed the knowledge on age limits to define a child, age of marriage and the age to consent for sexual activity in girls. Due to this inadequacy of knowledge either related with law or act, they are being vulnerable to be charged at the court of law.

Especially due to the lack of knowledge regarding legally accepted age limits among general public more children are prone to get abused by physical, sexual, and psychological means. This lack of knowledge has been evident by the increasing use of children for drug smuggling, prostitution and other criminal activities which is a rising issue that should be promptly addressed. ${ }^{\mathbf{1 2}}$

It should be stated that what need to be achieved through education cannot be achieved by harsh laws and stringent penalties.

On this background it is hypothesized that the inadequate knowledge regarding awareness of legally accepted age limits among school children, is a factor for children being abused and being victims and perpetrators of various crimes.

\section{OBJECTIVES}

To evaluate the awareness regarding the legally accepted age limits among school children and to assess any significant difference in awareness according to the gender and type of school (provincial, national).

\section{MATERIALS AND METHODS}

Data were collected from five schools in Kandy zone including both national and provincial schools during 2008-09 period from the 14-19 year age group. Classes from grade 9 and above were randomly selected to include 2 classes from each grade. Questionnaires were administered to the entire class and after a brief introduction they were asked to fill the questionnaires within $20-30$ minutes. Any queries that arose during filing up the questionnaires were clarified. A brief discussion and an awareness programme were carried out after collection of completed questionnaires.

Data were analyzed using Statistical software MINITAB.

\section{RESULTS}

Total study sample was 1812 . Out of that 7 questionnaires were discarded due to irrelevant answers. Results are displayed below (Table 01).

Out of $1805,1702(94.3 \%)$ were aware that there is an age limit to be known as a "child" and $1090(60.4 \%)$ had responded with the exact age limit. From the 1642 (91\%) who had responded positively for the age of marriage, only $773(42.8 \%)$ knew the exact age limit. The number decreased further down when it comes to the legally accepted age limit for sexual activities for girls to $555(30.7 \%)$.

$700(38.8 \%)$ of the total study sample were aware of the legally accepted age limit for buying alcohol/liquor while $61.2 \%$ were unaware. $1356(75.1 \%)$ responded correctly for the eligible age to get driving licence (see graph 01).

Table 01: Percentages of awareness in the total study sample

\begin{tabular}{|l|l|l|}
\hline Question & $\begin{array}{l}\text { Number of Correct } \\
\text { Responses }\end{array}$ & $\begin{array}{l}\text { Number of Incorrect } \\
\text { Responses }\end{array}$ \\
\hline 1. Age limit to be known as a child & $1090(60.4 \%)$ & $715(39.6 \%)$ \\
\hline 2. Age of marriage & $773(42.8 \%)$ & $1032(57.2 \%)$ \\
\hline 3. Age limit for sexual activities for girls & $555(30.7 \%)$ & $1250(69.3 \%)$ \\
\hline 4. Age to buy alcohol/liquor & $700(38.8 \%)$ & $1105(61.2 \%)$ \\
\hline 5. Age to get driving licence & $1356(75.1 \%)$ & $446(24.9 \%)$ \\
\hline
\end{tabular}




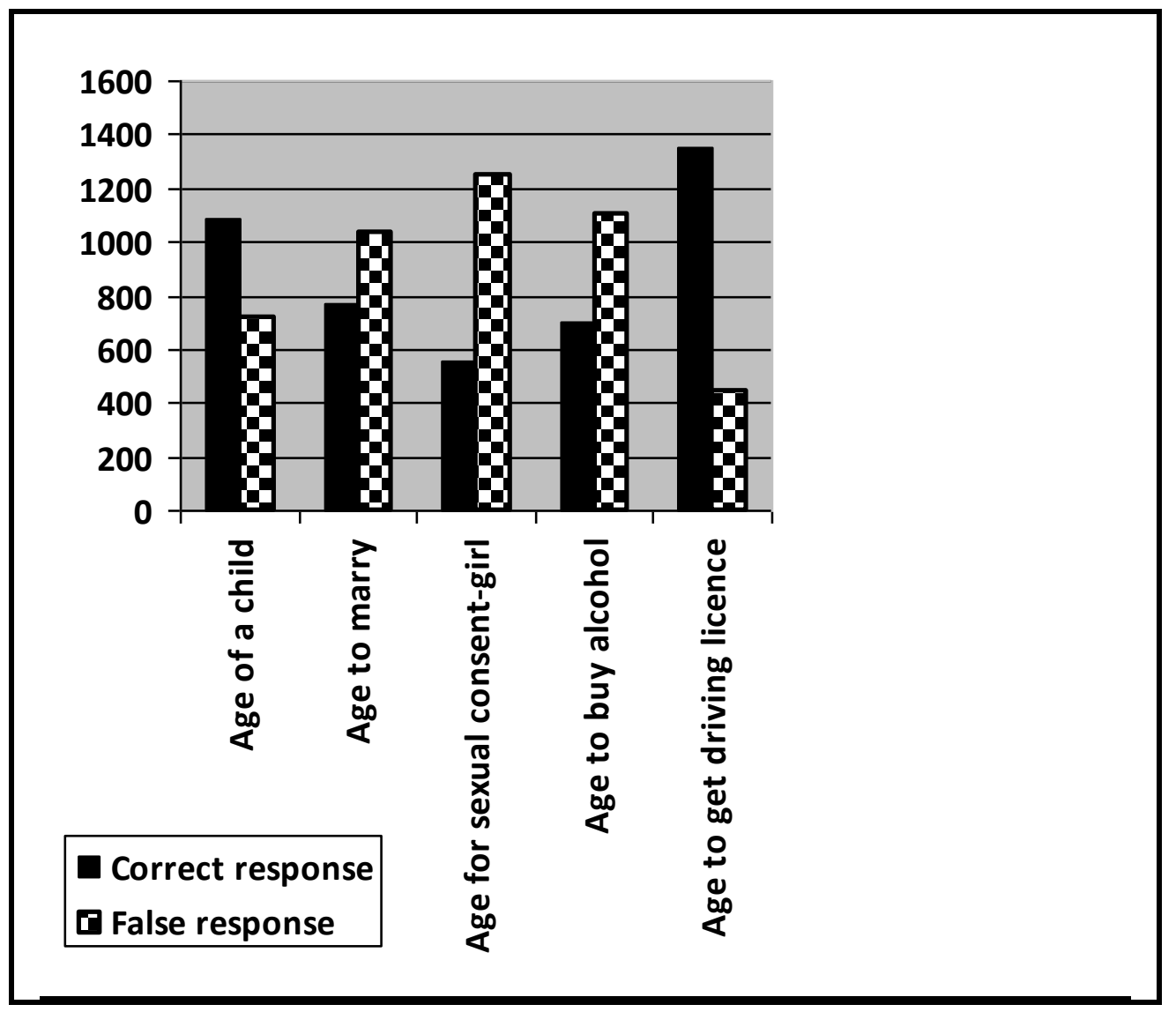

Graph 01: Number of response to the questions

Fishers exact test performed at 5\% significance (alpha $=0.05$ ) to find out whether there is a significant difference of awareness regarding the following aspects between children in national and provincial schools and between males and females of the selected sample.

\section{Legally accepted upper age limit to be called} a child.

2. Legally accepted age to marry

3. Legally accepted age for a girl to be able to give consent for sexual activity

4. Legally accepted age to be able to buy alcohol/liquor

5. Legally accepted age to be eligible for obtaining driving license

1. Comparison of national and provincial schools regarding the awareness of "Legally accepted upper age limit to be called a child

Fisher's exact test: P-Value $=0.172$

Results are not statistically significant at 5\% alpha.
There is no statistically significant difference in awareness between national and provincial schools.

2. Comparison of males and females regarding the awareness of "Legally accepted upper age limit to be called a chid" Fisher's exact test: P-Value $=0.493$

Results are not significant at $5 \%$ alpha.

Therefore there is no statistically significant difference in awareness between males and females.

3. Comparison of national and provincial schools regarding the awareness of "Legally accepted age for marriage"

Fisher's exact test: P-Value $=0.000$

Results are significant at $5 \%$ alpha.

Therefore students in national schools show a significantly higher knowledge.

4. Comparison of males and females regarding the awareness of "Legally accepted age for marriage"

Fisher's exact test: $\mathrm{P}$-Value $=0.000$

Results are significant at 5\% alpha. 
Therefore female students show a significantly higher knowledge on marriage age.

5. Comparison of national and provincial schools regarding the awareness of "Legally accepted age for a girl to give consent for sexual activity "

Fisher's exact test: P-Value $=0.000$

Results are significant at 5\% alpha.

Students in national schools show a significantly higher knowledge.

6. Comparison of males and females regarding the awareness of "Legally accepted age for a girl to give consent for sexual activity"

Fisher's exact test: $\mathrm{P}$-Value $=0.300$

Results are not significant at $5 \%$ alpha.

There is no statistically significant difference between awareness of males and females.

7. Comparison of national and provincial schools regarding the awareness of ". Legally accepted age to be able to buy alcohol/liquor"

Fisher's exact test: $\mathrm{P}$-Value $=0.141$

Results are not significant at 5\% alpha.

Therefore there is no statistically significant difference of awareness between national and provincial schools.
8. Comparison of males and females regarding the awareness of "Legally accepted age to buy alcohol/liquor"

Fisher's exact test: $\mathrm{P}-$ Value $=0.824$

Results are not significant at 5\% alpha.

Therefore there is no statistically significant difference of awareness between males and females.

9. Comparison of national and provincial schools regarding the awareness of "Legally accepted age to be eligible for obtaining driving license"

Fisher's exact test: $\mathrm{P}$-Value $=0.000$

Results are significant at 5\% alpha.

Therefore students in national schools show a significantly higher awareness.

10. Comparison of males and females regarding the awareness of "Legally accepted age to be eligible for obtaining driving license"

Fisher's exact test: P-Value $=0.702$

Results are not significant at 5\% alpha. Therefore there is no statistically significant difference of awareness between males and females.

Table 02: Summary of Results

\begin{tabular}{|l|l|l|}
\hline & $\begin{array}{l}\text { Whether there is a significant } \\
\text { difference in awareness } \\
\text { between National and } \\
\text { Provincial schools? }\end{array}$ & $\begin{array}{l}\text { Whether there is a } \\
\text { significant difference in } \\
\text { awareness according to } \\
\text { gender? (Male/ Female) }\end{array}$ \\
\hline 1. Age limit to be called a child & No significant difference & No significant difference \\
\hline 2. Age to marry & $\begin{array}{l}\text { Significantly higher awareness } \\
\text { in National schools. }\end{array}$ & $\begin{array}{l}\text { Significantly higher awareness } \\
\text { in female students }\end{array}$ \\
\hline $\begin{array}{l}\text { 3. Age for a girl to be able to } \\
\text { give consent for sexual activity }\end{array}$ & $\begin{array}{l}\text { Significantly higher awareness } \\
\text { in National schools. }\end{array}$ & $\begin{array}{l}\text { No significant difference in } \\
\text { awareness. }\end{array}$ \\
\hline $\begin{array}{l}\text { 4. Age to be able to buy } \\
\text { alcohol/liquor }\end{array}$ & No significant difference & No significant difference \\
\hline $\begin{array}{l}\text { 5. Age to be eligible in obtaining } \\
\text { driving licence. }\end{array}$ & $\begin{array}{l}\text { Significantly higher awareness } \\
\text { in National schools. }\end{array}$ & No significant difference \\
\hline
\end{tabular}

There was no significant difference in awareness about majority of issues, according to gender. However awareness regarding 3 out of 5 issues was significantly higher in National schools compared to provincial schools.

\section{DISCUSSION}

'Age' is an important factor in many of our activities as well as the medico-legal issues such as criminal offences. According to this 
study the school children were mostly aware of the age limits to be able to obtain a driving license $(75.1 \%)$. This may probably be due to increasing availability and use of personal vehicles form young ages in households. It was followed by the knowledge on age limits to be known as a child $(60.4 \%)$. Other age limits such as the age to marry, age for a girl to consent for sexual activity and age limit to buy liquor, the subjects had a grossly inadequate knowledge. However a study done recently, among victims and assailants of sexual abuse have showed that more than $90 \%$ in that target group were unaware of the legal age limit of a child. ${ }^{9}$ Furthermore more than $70 \%$ were unaware of the legal age limits of marriage and the age limit for a girl to consent for sexual activity. These victims mainly belonged to the school going age but their education level was very poor with majority belonging to no schooling/ up to grade 10 category.

The age limits to buy liquor was not known by about $60 \%$ of children. This may be due to low level of alcohol consumption during the school age. However it should be stated that children were being sold drinks irrespective of their age according to a study conducted in England. ${ }^{13}$ Although the social and cultural backgrounds are different in Sri Lanka the finding of selling liquor to underage should still be kept in mind since it can cause adolescents to be unaware of the legal age limits to buy them. This topic should need further studies in our setting.

The study has revealed that according to the gender, there was no significant difference in awareness about majority of the age limits that were assessed. The awareness on age to marry does have a significant difference between provincial and national schools as well as higher awareness in females.

Also there was a significant difference in awareness regarding the age of a girl to consent for sexual activity, between the national and provincial schools, being higher in students of national schools but the difference was not significant according to gender.

There are hardly any studies done, either locally or internationally, to assess the awareness of age limits particularly in school children.
However analysing the numerous studies done to assess the education level of victims and perpetrators of sexual abuse, majority of victims were of school going age and the studies have revealed that the education level of both victims and perpetrators were very low. ${ }^{6,7}$, 8,9

Interestingly a study done in Saudi Arabia has revealed that the awareness of the majority of the school professionals also have a low to intermediate level of awareness of child maltreatment. ${ }^{14}$ Considering that school professionals play a significant role in children's lives, as they spend a great deal of time with them and are hence essential to protecting and identifying those in danger or at risk, the need to make them aware is also critical in decreasing the number of cases of child abuse.

These study results can be utilized in conducting awareness programs for school children with the addition of knowledge to the school curriculum. And also the provincial schools should be given priority in areas where they lack knowledge significantly.

In prevention of child abuse, parents have a vital role. But still the vast majority of the people in the country are not aware of the changes brought about in the law in $1995 .^{15}$

Also studies have highlighted the minimal and inadequate knowledge and practice in parents regarding this matter. ${ }^{16}$ These findings should be strictly taken into account and the need for child abuse prevention education programmes for parents, to improve their awareness is a growing requirement.

\section{CONCLUSION}

In conclusion, majority of school children in our study sample were unaware of the legally accepted age limits on various issues. Therefore in general the awareness regarding legally accepted age limits is insufficient in school children and this issue needs to be addressed. 


\section{SUGGESTIONS}

We suggest the need to include an introduction to legally accepted age limits into school curriculum as one method.

In addition, as awareness in Provincial schools is significantly lower when compared to the national schools, we suggest the need to conduct educational programmes at provincial level by relevant authorities.

Also since there are no studies that have evaluated school professionals' awareness on the matter, it would be a future topic to plan a study, which would ensure the protection of children at the school level.

\section{REFERENCES}

1. Elders and Childrens' Day Today, Daily Mirror, 2009. October 1:1

2. Denial, Managing child abuse a hand book for medical officers, World Health Organization:2004:11

3. Kirinde C., Child abuse cases cries out in high courts. The Sunday Times, 2009. October 18:3.

4. De Silva D.G.H, Christopher H., A Manual for medical officers in Sri Lanka.2000;1-2.

5. Anjani T. Sri Lanka Struggles to Contain a Growing Epidemic of Child Abuse. Time:World,13th August. 2013 Available at: http:/http://world.time.com/2013/08/13/sri-lankastruggles-to-contain-a-growing-epidemic-of-childabuse/ [Accessed 20 Sep 2013]

6. Ganguly RP, Patron KK, Jha T, Bhattacharya AR, Sarkar D, Sexual assault and its medical, Medicolegal and Social aspects-a retrospective study. $J$ Indian Med Assoc. 2010;108(10): 682-90.

7. Al-Azad, M., Rahman, Z., Ahmad, M., Wahab, M., Ali, M. and Khalil, M., Socio- demographic characteristics of alleged sexual assault(Rape) cases in Dhaka city. Journal of Armed Forces Medical College. 2011, 7(2), pp. 21-24

8. Manzoor, M, Hashmi, N.R., and Mukhtar, F , Medico-legal Aspects of Alleged Rape Victims in Lahore, Journal of the College of Physicians and Surgeons Pakistan, 2010, 20 (12), pp. 785-78
9. Dassanayake P, Vadysinghe A, Abeysekera Y, Manoratne N, Nissanka W, A study on awareness of medico-legal aspects among victims and assailants regarding alleged sexual assault, Annual scientific sessions, Medico-legal society of Sri Lanka. 14th September, 2013, pp. 37

10. Colombage SM, Dassanayaka P.B, Waidyaratna D.L., A study on child abuse in Anuradhapura, Colombo South and Ratnapura. 2005; 11.

11. 3 children raped daily in Sri Lanka. The Sunday Times. 10th October, 2010.[online]

Available at: http://www.sundaytimes.lk/ 101010/News/nws_02.html\#top.[Accessed 20 Aug 2013]

12. 6 Child labourers in drug smuggling. Sri Lanka Mirror,13th June. 2013

Available at: http://srilankamirror.com /news /8114-child-labourers-in-drug-smuggling [Accessed 30 Aug 2013]

13. Maisey A, Davies G. Lessons to be learned: a case study approach, Underage drinking in adolescents. The Journal of the Royal Society for the Promotion of Health. 2003; 123: 52-54.

14. Albuhairan F, Inam S, Aleissa M, Noor I, Almuneef M., Self-reported awareness of child maltreatment among school professionals in Saudi Arabia: Impact of CRC ratification. Child abuse and neglect. 2011; 35: 1032- 1036

15. Parliament of the Democratic Socialist Republic of Sri Lanka, Penal code (Amendment)Act No 25 of 1995, 31st October ,1995.

16. Chen J., Chen D., Awareness of child sexual abuse prevention education among parents of Grade 3 elementary school pupils in Fuxin City, China. Health Education Research. 2005; 20 (5): 540547.

\section{ACKNOWLEDGEMENTS}

Statistical assistance - Dr. C.D. Wickramasinghe, Department of Forensic Medicine. 